\title{
MICHEL FOUCAULT O LA PROBLEMATIZACIÓN DEL PENSAMIENTO. ENTREVISTA CON MARCO DÍAZ MARSÁ (11 DE ENERO DE 2019) ${ }^{1}$
}

\author{
Entrevista: Yesurún Moreno ${ }^{2}$ \\ Universidad de Barcelona, España.
}

Recibido: 20 de febrero de 2021. Aprobado: 12 de abril de 2021.

Marco Díaz Marsá es Doctor en Filosofía y Profesor Contratado en el Departamento de Lógica y Filosofía Teórica de la Universidad Complutense de Madrid. Asimismo, es Coordinador de las Titulaciones de Doble Grado en Derecho y Filosofía y Ciencias Políticas y Filosofía de la UCM. Fue becario doctoral del Ministerio de Educación y becario postdoctoral de la Fundación Caja de Madrid. Es miembro de la Red iberoamericana Foucault y de los proyectos de investigación Naturaleza humana y comunidad IV y La deducción trascendental de las categorías: nuevas perspectivas, y forma parte de los grupos de investigación UCM GINEDIS y "Metafísica, crítica y política". Autor de numerosos artículos sobre Foucault en revistas especializadas, entre sus libros cabe destacar Modificaciones. Ontología crítica y antropología política en el pensamiento de Foucault (Escolar y Mayo. Madrid. 2014), Ley y ser. Derecho y ontología crítica en Foucault (Escolar y Mayo. Madrid. 2016) y Foucault y la cuestión del derecho (coordinado junto con J. L. Pardo. Guillermo Escolar ed. Madrid. 2017).

Yesurún Moreno: ¡Buenas tardes, Marco! Trataré de ser lo más breve posible... En primer lugar, agradecerle que me haya dedicado este tiempo pues soy conocedor de la carga de trabajo que tiene a estas alturas de curso.

\footnotetext{
${ }^{1} \mathrm{Al}$ transcribir la entrevista he decidido respetar la atmósfera de oralidad que se creó entre el entrevistado y yo.

${ }^{2}$ Yesurún Moreno Gallardo. Ciencias Políticas y de la Administración en la Universidad de Barcelona. En 2019 realizó el programa SICUE en la Universidad Complutense de Madrid. $\mathrm{Su}$ área de investigación es la filosofía y teoría política. Diplomado en la Especialización: "Estado, Gobierno y Democracia" del Consejo Latinoamericano de Ciencias Sociales (CLACSO) y el programa UCM de Madrid: "Análisis crítico de la economía capitalista". Ha cursado también el XVII Edición del Curso \&quot; Actualidad de la política exterior española\&quot; (CEI International Affairs).

E-mail: yesurunmoreno@gmail.com ORCID: 0000-0002-5583-3478
} 
Marco Díaz: ¡Buenas tardes! Adelante, venga, dispara. Pregúntame a ver...

Yesurún Moreno: Para comenzar, ¿quién es Marco Díaz Marsá? ¿dónde se cría? ¿por qué decide hacer filosofía?

Marco Díaz: Bueno, buena pregunta... ¿Por qué decidí hacer filosofía? Ya casi ni me acuerdo... Fue una de esas pasiones que se iniciaron cuando yo tenía dieciséis, diecisiete años, leyendo curiosamente a Nietzsche. Digo curiosamente porque últimamente Nietzsche no me interesa tanto como me interesaba en esa época, pero fue esta lectura, aderezada con las ensoñaciones románticas de Goethe, -que luego me llevaron a amar a Hegel, y tras pasar por él, a Kant- lo que me condujo a la facultad de filosofía y, una vez estuve allí, me empecé a interesar bastante -a partir de mi tercer curso- por cuestiones de metafísica y ontología, al asistir a las clases de la persona que tuvo la generosidad de hacer el prólogo de mi primer libro sobre Foucault, Modificaciones (2014), me estoy refiriendo a Juan Manuel Navarro Cordón.

¿Qué decir de Navarro Cordón en el espacio abierto por tu pregunta? Respondo sencillamente: Navarro es mi maestro y mi referencia permanente para una forma de cuidado de los otros que no pretende generar dependencias ni manipulaciones, sino autonomía. Mi deuda para con él no puede expresarse mejor que en esa manera tan bella en que lo hiciera Foucault refiriéndose a su compromiso con Jean Hyppolite: a él le debo "todo". Si nos extrañáramos de ese "todo", en nuestra propia lengua tendríamos que preguntarnos: ¿Qué quiere decir "todo"? Y tendríamos que preguntarnos sobre el modo en que la filosofía es un "todo", un todo acabado. Como dijo Kant: "o todo o nada".

La escuela de Navarro Cordón es una escuela exigente, no del rigor descarnado de los "textos", sino de las prácticas de lectura, escritura y discusión que median en el pensamiento (en el sentido de que esas prácticas constituyen su medio). Una escuela que tiene raíces de comprensión hermenéutica fundamentalmente kantianas y heideggerianas.

Entonces, a partir de esas bases -e incitado por las clases de Navarroempiezo a leer a Foucault. Y, además, muy espoleado por unas declaraciones que Foucault hace en su entrevista final. En esa entrevista Foucault dice: para mi Heidegger es el filósofo esencial. Algo impactante ¿no? Al menos para los que leíamos a Foucault en esa época (me estoy refiriendo a los años 1994-1995). O sea, última entrevista, una entrevista que concede como gesto de reconocimiento hacia Deleuze (de quien se había enemistado por razones, y esto me parece importante, teóricas y políticas) a un discípulo de este. Ahí dice cosas muy, muy interesantes...

Entre ellas dice: he leido a Nietzsche, pero Nietzsche por sí mismo no me decía nada; luego empecé a leer a Heidegger y la combinación de Heidegger 
y Nietzsche tuvieron para mí un efecto absolutamente detonante. Y es ahí en ese contexto donde Foucault señala que para él Heidegger es el filósofo esencial. Y da una clasificación muy interesante de los filósofos con los que se relacionaba. Dice: hay tres tipos de filósofos, filósofos que conozco y de los que hablo (ahí entraría, por ejemplo, Nietzsche, La genealogía, la historia texto que se publica en el año 1971...); filósofos que no conozco de los que no hablo y, finalmente, filósofos que conozco, pero de los que no hablo, pero que forman parte de un haber, de un sustrato, a partir del cual leo todo lo que hay (y ahí estaría Heidegger, sin duda).

Pero también en sus últimos pronunciamientos -esto lo conocerás-, cuando Foucault presenta su proyecto crítico de una ontología de la actualidad, como una ontología crítica que es también una ontología histórica de nosotros mismos, se pregunta en qué lugar ha de ubicar su proyecto; ese lugar no es otro que el de la tradición kantiana.

Entonces tenemos ahí dos referencias fundamentales en la obra de Foucault a partir de las cuales yo he tratado de armar mi lectura.

Por otra parte -como bien sabrás- Foucault en el año 1961 defiende una tesis complementaria a su tesis principal que fue Historia de la locura (1961). Esa tesis complementaria era una traducción y una introducción a la Antropología desde un punto de vista pragmático (1798) de Kant. Este texto que está ya publicado en castellano, bajo el título Foucault, lector de Kant (2010) en la Editorial Siglo XXI, me permite armar la tesis que yo defiendo. En esta introducción vemos esbozarse, en una lectura del Opus Postumum de Kant, una noción de mundo como sistema de actualidad. Y lo interesante es que todo aquello que dice Foucault a propósito de Kant en esa introducción del año 1961, sobre una noción de "mundo" que es un sistema concreto de pertenencia, un sistema de actualidad, es "reactivado" por Foucault en sus últimos pronunciamientos cuando se refiere a su propio proyecto. Y bueno, a partir de estas pistas he tratado de cimentar una lectura de raigambre ontológica y matriz kantiana, pero un Kant -como ya podrás adivinar por lo que te estoy contando- muy atravesado por Heidegger. Es un Kant muy heideggeriano, no es el Kant de Heidegger jojo!, sino un Kant heideggeriano. Es decir, un Kant en el que todas estas cosas que presenta Heidegger sobre "ser y libertad" en Ser y tiempo (1927) y en otros textos, como: Kant y el problema de la metafísica (1929); De la esencia de la verdad (1930) De la esencia del fundamento (1929) o ¿Qué es Metafísica? (1929), aparecen, incluso, diría yo, mejor elaborados que en Heidegger, ya en Kant.

Entonces, estos son un poco los mimbres de mi lectura, bueno, es la tradición de lectura en la que yo me inserto y el estímulo que ha hecho que me meta en filosofía y en esas cosas de ontología y metafísica, aparentemente tan 
abstractas, pero que en el fondo tienen todo que ver con la actualidad y con, por ejemplo, cuestiones como la que tú has planteado del cuerpo y demás.

Yesurún Moreno: Me resulta muy llamativo lo que comentaba acerca de la lectura "insípida” de Nietzsche... ¿Podríamos -aunque no resulte del todo esclarecedor o de cabal importancia-decir que Foucault fue realmente estructuralista?

Marco Díaz: A ver... Foucault es difícilmente encasillable, difícilmente encasillable, por ejemplo, en un rígido estructuralismo del corte propio de Levy Strauss, tal como lo leía Foucault, pero tampoco sería fácilmente ubicable en un pragmatismo en el sentido que le confiere Deleuze leyendo a Foucault. Tampoco creo que sea un filósofo positivista, porque hay una cierta manera de entender lo trascendental en Foucault que no puede ser ignorada y que yo he perseguido mucho. Se trata de la idea endiablada y difícil de a priori histórico, idea que en sus últimos textos retoma bajo la noción de problematización. Tenemos aquí una noción que tiene un cierto carácter trascendental, posibilitante, pero no conceptual (no es un concepto universal) que Foucault perfila en El cuidado de la verdad como la "forma común" y "esencial" de una experiencia históricamente singular.

Como te decía es un asunto muy endiablado que exige definir muy bien y responder a las cuestiones: ¿Qué quiere decir pensar en Foucault? y ¿cuál es la sistemática de su pensamiento? Pensar es problematizar, es experimentar, pero pensar se articula a partir de tres ejes, indisociables, pero irreductibles: saber, poder y relación de sí consigo (en la relación con los otros y al través de una relación con los saberes) como los tres ejes que constituyen y articulan la experiencia del pensamiento.

En definitiva, es muy difícil encasillar a Foucault, es decir, Foucault era como una esponja, lo absorbía todo, no hay por donde cogerle. Por ejemplo, Foucault criticó mucho a un cierto marxismo, a una cierta ortodoxia marxista que él llama "la comunistología", en una lectura de Marx muy desde el joven Marx -por cierto- dominada por una metáfora que Marx apenas utiliza, solamente en sus textos de juventud, que es la metáfora de la superestructura y la infraestructura. En este punto Foucault critica al marxismo. Pero ese Marx no está en El capital, por ejemplo. Es muy interesante observar, en relación a Vigilar y castigar (1975) -que es el texto que más te está interesando a ti ahora para tu ensayo- que Foucault en "Los cuerpos dóciles" se hace cargo de toda una serie de capítulos del primer libro de El capital, en concreto de toda una serie de secciones del mismo (si no recuerdo mal las secciones que se refieren al trabajo social, a la maquinaria y a la división del trabajo) donde Marx lo que cuenta justamente es eso que tanto interesa a Foucault cuando elaboraba Vigilar y castigar, a 
saber: la constitución política de la fuerza productiva. La constitución del trabajo social, de los gestos y movimientos que comporta el trabajo social, la temporalidad que comporta el trabajo social, también su espacialidad... Es decir, Foucault está contando que eso del tiempo, el espacio y la actividad del capital es algo producido, producido técnica-políticamente.

Y en esa medida no podemos pensar que -lo dice también en algún lugartrabajamos porque el trabajo sea algo así como la esencia del hombre, algo que podríamos encontrar en el joven Marx. Trabajamos, más bien, porque hemos sido obligados a trabajar en el modo de producción capitalista. Y Foucault está reproduciendo además hasta a nivel estilístico estas cosas que cuenta Marx en El capital. Esto lo digo como ejemplo para que te hagas una idea de lo difícil que es encasillarlo...

Hay un Marx del que Foucault está todo el rato bebiendo y que es irrenunciable. Podríamos decir lo mismo de un cierto Althusser, podríamos decir, desde luego, lo mismo de Heidegger, de Kant, incluso de Hegel. Hegel también aparece mucho en sus textos. Yo no lo ubicaría en el estructuralismo y si me apuras ni siquiera tampoco en el postestructuralismo. Todo esto no son más que etiquetas, que forman parte del terreno de la disputa -de la polémica- de los "nombres", no de la problematización y la discusión del pensamiento. Hay que ser nominalista cuando se lee a Foucault y trabajar en el espacio de lo concreto.

Yesurún Moreno: Resulta interesante la dimensión técnico-política que sugiere, puesto que guarda estrecha relación con el paso -que según él- experimenta la historia penal entre las formas "suplicio" y "castigo". ¿Qué lugar ocupa la libertad en estos términos?

Marco Díaz: En efecto, la producción de libertad. Ahí de lo que se está tratando es de lo siguiente: eso que se vive como libertad no es más que la cobertura ideológica necesaria para que un poder, que es en última instancia dominación, se instale y perpetúe.

Lo que sucede es que Foucault, más o menos a partir del año 1978, cambia de perspectiva y esto también resulta interesante. Es lo que he tratado de apuntar en mis trabajos: desplaza su modo de problematización. A partir de un determinado momento, Foucault va a distinguir muy precisamente poder y dominación (no sólo poder y violencia). Caben relaciones políticas que tienen en la libertad su condición de existencia.

Entonces, ¿Qué quiere decir eso? y ¿cómo afecta todo esto al problema del cuerpo y la resistencia tal y como se planteaba en obras anteriores a 1978 como, por ejemplo, en Vigilar y castigar?

En Vigilar y castigar (1975) hay un problema enorme con la resistencia, en general sucede con el Foucault de la primera mitad de los setenta. 
También en el primer volumen de Historia de la sexualidad (1976). Es decir, Foucault considera que hay resistencias, es la fórmula que Foucault emplea en el capítulo "método" de "La voluntad de saber": "donde hay poder, hay resistencia". Hay resistencia, las resistencias constituyen un factum, además material y corporal. No son resistencias que pasen por una mera toma de conciencia o algo así. Pero claro, sentadas las bases de su comprensión del poder propia de esta época difícilmente se ve cómo puede haberlas (las resistencias). Si el poder es una instancia omnímodamente productiva, tal como se presenta en una comprensión abstracta y unilateral de Vigilar y castigar, en concreto, centrada en lo que Foucault dice en "Los cuerpos dóciles"; o sea, si finalmente los cuerpos humanos son una pasta informe, maleable que puede ser descompuesta en mínimos elementos y recompuesta de acuerdo con criterios de optimización económica, si no hay nada que pueda resistir a esa construcción, si no hay nada que pueda limitarla, no se entiende en qué sentido Foucault puede afirmar, al mismo tiempo, que hay resistencias. Hay aquí una aporía.

Entonces, "el cuerpo", el cuerpo que resiste es un cuerpo irreductible, inanalizable que, por ello, debe tener una constitución. Y esto es lo que a mí -personalmente- me cuesta mucho ver en Vigilar y castigar, si no ensamblamos este texto en la sistemática del pensamiento foucaultiano ${ }^{3}$. Es lo que considero paradójico en el planteamiento del poder en el francés, encarado al margen de las dimensiones constitutivas de la verdad y de la relación de sí consigo. Por un lado, el poder es una instancia omnímodamente productiva, pero, por otro lado, Foucault afirma que hay resistencias. ¿Cómo puede haberlas? Tal es la paradoja.

Yesurún Moreno: Esto me recuerda a la crítica que le hace a Foucault Carlos Fernández Liria en Sin vigilancia y sin castigo (1992), ¿no es cierto?

Marco Díaz: ¡Exactamente! Por eso a mí el libro de Carlos me interesó tanto... Carlos es mi compañero de despacho, y tengo una relación intelectual muy estrecha con él, y también de amistad. Recuerdo, cuando empezaba a leer a Foucault, que yo no entendía lo que pretendía decir Fernández Liria, me parecía literalmente una locura. De hecho, cuando me enteré de que el nombre de Carlos Fernández Liria se barajaba entre otros posibles para ser incluido entre los miembros de mi tribunal de tesis doctoral, recibí la noticia con inquietud. Pero más tarde, con el tiempo, leyéndolo con más detenimiento, me di cuenta de que tenía razón. Pero ¡ojo! que tenía razón matizándolo de la siguiente manera: creo que todo lo que dice Carlos

${ }^{3}$ La peculiaridad de esta "sistemática" es trabajada por Marco Díaz Marsá en el primer capítulo de su libro Modificaciones. Ontología crítica y antropología política en el pensamiento de Foucault (Escolar y Mayo: Madrid, 2014). 
acerca de Vigilar y castigar, me parece que, salvando cosas de detalle es correcto... Ahora, yo ya no sé si lo que sostiene Carlos se podría indicar de ese Foucault que cambia radicalmente, y esto hay que subrayarlo, entorno al año 1978, en el marco de sus estudios de la gubernamentalidad, donde va a introducir el elemento de la libertad en su analítica de las relaciones de poder. Pero cuidado, no en un sentido, digamos, neoliberal (estoy pensando en el libro de Daniel Zamora ${ }^{4}$ sobre Foucault. De este libro no hay ya mucho que decir después de la refutación magistral que del mismo ha realizado Rodrigo Castro). Yo defiendo, tratando de seguir con cuidado las transformaciones involucradas en su pensamiento, que la libertad que plantea Foucault en sus últimos textos retoma la corriente que marca en $E l$ nacimiento de la biopolítica (1979) como la tradición derrotada, frente a la tradición triunfante liberal. Me estoy refiriendo a la tradición revolucionaria, rousseauniana. Todo esto que señalo, hay que considerarlo, claro está, con muchas precauciones críticas y metodológicas.

Yesurún Moreno: ;Claro! hace poco empleaba en un trabajo una analogía entre Foucault y Rousseau, corrijame si me equivoco: el "sujeto sujetado" foucaultiano se asemeja muchisimo a la figura retórica rousseauniana que reza: "el hombre es libre, pero en todas partes se halla encadenado".

Marco Díaz: Se trata de una cuestión muy complicada... el término sujeto en Foucault tiene diferentes acepciones. Desde luego, cuando el francés habla de libertad en la primera mitad de los años 70, en todos esos textos en los que se refiere al saber-poder como un dispositivo que produce sujetos, se trata siempre de una libertad y un sujeto sometido y, por tanto, en ningún caso de una libertad de corte republicano. Se trata entonces de una producción del poder a través de relaciones con la verdad (las ciencias humanas) que producen sometimiento.

$\mathrm{Y}$ a esta misma idea se ajusta, bajo ciertas modulaciones, abiertas por la cuestión biopolítica, lo que en 1982 en un texto muy interesante titulado El sujeto y el poder Foucault denomina los dos sentidos de la palabra sujeto. Dice, sujeto tiene dos sentidos: (I) sujeto sometido a otro mediante el control y la dependencia y (II) sujeto fijado a su propia identidad por la conciencia o el conocimiento de sí. Aquí se trata de dos formas de sujeción, de dos formas de "sometimiento". En el primer caso se trata claramente de su sometimiento a un otro, pero en el segundo se trata de un sometimiento de sí por sí mismo, ese sometimiento que llamamos subjetividad. Pero hay que tener en cuenta que Foucault inmediatamente después va a señalar que

${ }^{4}$ Zamora, Daniel y Behrent, Michael C. (comps.), Foucault y el neoliberalismo, Amorrortu Editores, 2018. 
con ella se trata de todo lo que liga al individuo a sí mismo, y asegura así su sumisión a los otros. Es, por tanto, un gobierno de sí político de carácter heterónomo, que, en consecuencia, ha de encuadrarse dentro de lo que Foucault llama "el gobierno de los otros".

Yesurún Moreno: Esto lo retomará al final de su trayectoria ¿no?

Marco Díaz: ¡Claro! pero de otra manera. Al final de su itinerario nos encontramos con otro texto que libera una forma diferente de subjetivación. Me refiero a una entrevista titulada Une esthétique de l'existence (creo que no existe traducción de la misma).

Allí indica que el sujeto puede constituirse a través de prácticas de dominación o de una manera más autónoma. Hay que pensar con cuidado lo que está implicado en esta noción de autonomía: ya no se trataría aquí de un gobierno de los otros, en cualquiera de sus formas, sino de una subjetivación a través de prácticas de libertad. Pero no concebidas de un modo puramente ético-estético, como parece sugerir el título de la entrevista, como la práctica permanente de un no ser gobernado en absoluto. Tenemos aquí una noción de sujeto autónomo, cuyo carácter político, queda claramente expuesto en La ética del cuidado de sí como práctica de la libertad (1984) $)^{5}$. no se trata aquí de un gobierno de sí que es un gobierno de los otros (heteronomía en el gobierno de sí), ni de un gobierno de sí que es la condición ética para el gobierno de los otros (el gobierno comprendido bajo el "modelo Alcibíades"), sino de un gobierno de sí, bajo la condición política de una pluralidad originaria (que implica siempre el conflicto del factum de esa heterogeneidad radical y corporal en un mundo limitado: no hay semántica política común, dice Foucault), que es idéntico a un gobierno de los otros: un gobierno sí que es, al mismo tiempo y sin contradicción, un gobierno de los otros. No estamos aquí ante un paradójico "soberano sumiso", sino ante un ciudadano. En suma, un gobierno de sí en que se expresa lo que Foucault llama en El cuidado de la verdad (1984) una voluntad política ${ }^{6}$.

Yesurún Moreno: Al hilo de lo que sugiere, no recuerdo en qué parte lo lei, probablemente sea inexacto, pero Foucault viene a defender que no puede existir poder sin libertad en el sentido en que el sujeto que estuviera completamente sujeto en realidad es un esclavo.

${ }^{5}$ L'éthique du souci de soi comme pratique de la liberté, entrevista con H. Becker, R. Fornet-Betancourt, A. Gómez-MüUer, 20 de enero de 1984.

${ }^{6} \mathrm{Y}$ a este respecto habría que añadir que la crítica foucaultiana ejerce una función de ciudadanía. En esta línea, puede consultarse Marsá, Marco, "Poder, libertad y derecho a partir del último Foucault: consideraciones sobre la noción de 'gobierno de sí'”, Dorsal: Revista de Estudios Foucaultianos, Número 7, diciembre 2019, pp.11-31, ISSN: 0719-7519. 
Marco Díaz: Bueno, él dice exactamente que la esclavitud no es una relación de poder si el esclavo en última instancia no es libre, no es capaz de actuar. Es un asunto muy interesante. Es la cuestión de El sujeto y el poder (1982), y de su desfase con respecto a La ética del cuidado de sí como práctica de la libertad (1984). Aquí habla también como en El sujeto y el poder de la libertad como condición del poder, pero la libertad aquí adquiere un nuevo sentido. Hay, por tanto, un desfase entre el texto del 82 y el texto del 84.

En El sujeto y el poder (1982), Foucault señala que la libertad es la condición tanto del poder como de la resistencia, que entre el poder y la libertad no hay un cara a cara, una relación digamos de exclusión mutua (donde hay poder no hay libertad, donde hay libertad no hay poder), sino que existe un juego mucho más complejo. Es ahí donde dice que la libertad es la condición del poder en dos sentidos: (I) en primer lugar como precondición, en el sentido de que para que se ejerza el poder tiene que haber actividad y acción en el polo en el que se ejerce el poder, (II) pero también en el sentido de que ella es su soporte permanente, es decir, para que el ejercicio del poder sea productivo, para que el poder tenga efectos productivos y esto, ante todo, en sentido económico, es necesario que en el polo sobre el que se ejerce el poder haya libertad. Por eso, dice Foucault que el poder se ejerce entre sujetos libres y en la medida en que son libres. El poder es un modo de acción que se ejerce sobre acciones. Pero la presuposición que opera aquí es que "poder" es "dominación", no una dominación violenta, que anula y aniquila al otro, sino productiva (es un gobierno-conducta) y para ello, es necesario que el otro, aquel sobre el cual se ejerce el poder, tenga libertad de acción como conducta (cosa por cierto muy diferente a la libertad de opción).

Hablamos de la dominación específica exigida en un sistema de producción capitalista de competencia como el nuestro. Se precisa de la "libertad", desde luego de movimientos, pero también y ante todo del libre flujo de deseos. La libertad del deseo es fundamental para el adecuado funcionamiento de un sistema de producción ilimitada tal como este. Todo aquí, al menos en las sociedades occidentales, operaría de forma suave: no se trata tanto de ordenar y disciplinar, cuanto de producir un medio social de incitaciones donde los sujetos reaccionan de manera sistemática las modificaciones de las variables del medio. Es a esto a lo que Foucault llamaba "regulación". Un Estado regulador, como dice Frédéric Gros, no se dirigirá a voluntades, no ordenará voluntades ni expresará voluntad pública alguna, se dirigirá a naturalidades. El pueblo no se regula, se regulan 
poblaciones. Los nacimientos, por ejemplo, no son asunto de la voluntad, sencillamente los hay.

La natalidad es un fenómeno que pertenece a las dinámicas internas de la vida, a sus deseos, a sus necesidades...Un Estado regulador promoverá la natalidad ofreciendo, por ejemplo, prestaciones a las familias numerosas. Se trata, entonces, de ajustar un elemento de la realidad (la natalidad) con otro elemento de la realidad (el subsidio). Se ha de mantener siempre un equilibrio y armonizar elementos naturales. Se trata de lo que Foucault llama en su curso Seguridad, territorio y población (1978) "el juego de la naturaleza con ella misma". En este marco, el Estado regulador ha de evitar toda intervención de una voluntad que se considerará arbitraria y paralizante. Pero, lo que es muy importante entender es que este funcionamiento armónico y espontaneo, auto-regulable, descansa en la producción del medio social adecuado para el capitalismo de la competencia. Y esta producción se asienta en una destrucción de las voluntades humanas y, desde luego, también de toda forma de voluntad pública. En esta devastación se asienta la armonía securitaria de la utopía liberal, de la espontaneidad natural de los mercados, pero también la utopía de lo que se ha llamado el internet de las cosas (Internet of Things) 7 . Lo interesante del planteamiento de Foucault en sus últimos textos es que en ellos se trata de activar voluntades, sin, por ello, vehicular una teoría humanista del sujeto, entendida en un sentido decimonónico.

Yesurún Moreno: Sin embargo, en el sujeto, como constructo inmediato del poder, al estar sujetado, normativizado, también los deseos son condicionados.

Marco Díaz: Sí, pero no es una normalización disciplinaria. La normalización disciplinaria es mucho más rígida. Corresponde al modelo de producción industrial en serie, y con ella se trata de la producción de sujetos a partir de una norma dada. Aquí no hay normas dadas. La norma -digamos- se extrae como una segregación de la experiencia y en forma estadística. En realidad, hablamos del funcionamiento propio del poder en sociedades que no son totalitarias como las nuestras, sino securitarias. Lo cual no quiere decir que no haya dominación, pero la dominación no es una dominación totalitaria, sino securitaria, es decir, una dominación que para su funcionamiento exige -Foucault lo dice expresamente- cierta tolerancia, cierta benevolencia con los diferentes e incluso más: la optimización de las diferencias.

${ }^{7}$ Aquí las cosas pueden devenir sujetos porque ante todo los seres humanos han devenido objetos. Véase Gros, Frédéric, Le principe sécurité, Paris, Gallimard, 2012, sección "regulación", capítulo bioseguridad. 
Y por aquí llegamos a la gran paradoja del Homo oeconomicus: el hombre libre eminentemente gobernable. El hombre intocable del laissezfaire, el hombre que responde solo a su interés, un interés que armoniza "espontáneamente" con el interés de los otros, es el hombre objeto de toda una serie de tecnologías que actúan sobre el medio, que reacciona de manera sistemática a las modificaciones de sus variables. Se trata de la gran paradoja de la acción y la voluntad, como conducta económica, tal como fue comprendida por la escuela de Chicago, a partir de lo que Foucault llama su texto prínceps: La acción humana. Tratado de economía, de Von Mises. Una determinación consecuente de la acción humana como conducta económica y la consiguiente identificación del objeto económico con cualquier actividad humana, casarse, cometer un crimen, criar hijos y darles afecto, etc..., exige ir mucho más allá de la definición de "actividad económica" que tiene su suelo en el texto de Von Mises. La determinación de la acción económica como "asignación de recursos escasos a fines alternativos" permite extender el análisis económico a toda conducta finalista que implique una elección estratégica de medios, vías e instrumentos, a toda conducta "racional" (bajo esta corta noción de racionalidad), pero aún no es lo suficientemente general. Y en este punto Foucault centra su atención en la definición de Gary Becker, que pone de manifiesto la paradoja del Homo oeconomicus. La radicalidad y consecuencia de esta definición es aplastante: "económica" -y economizable- será toda conducta que constituya una reacción no aleatoria a lo real, una respuesta sistemática a las variables del medio. Y por el camino de esta definición podrá armonizarse la ciencia económica con toda una serie de tecnologías comportamentales con las que no se trata tanto de la comprensión de la significación económica de los fenómenos sociales, cuanto de saber cómo podrán economizarse las conductas: cómo, dado un determinado juego de estímulos, se podrán provocar respuestas sistemáticas, mediante mecanismos de refuerzo, que pueden ser conocidas, controladas y alteradas introduciendo otras variables de comportamiento. Esta es la paradoja del Homo oeconomicus: a través de la definición radical de Gary Becker se descubre como un animal de laboratorio sin esa voluntad y libertad que afirma tener. Pero El análisis de la voluntad en Foucault es completamente diferente al de las escuelas neoliberales...

Yesurún Moreno: Lo entiendo como un cambio en la tecnología del poder...

Marco Díaz: En efecto, aquí entran categorías que no entraban en una concepción disciplinaria del poder. La flexibilidad aquí es importantísima. La flexibilidad económica de la que tanto oímos hablar en la actualidad es en resumidas cuentas un concepto fundamental en las sociedades securitarias. 
Sennet se ha referido, por ejemplo, al capitalismo actual postfordista, al postcapitalismo como aquella forma de capitalismo que se define justamente por su carácter nómada, flexible, en el que tiene lugar una producción de subjetividad que -digamos- no tiene una competencia fija y determinada como ocurría en las sociedades fordistas. Se trata de sujetos ágiles, adaptativos, emprendedores, que están dispuestos, por ejemplo, a viajar continuamente, y, por tanto, al desarraigo total. Esto no significa que en nuestras sociedades se abandone la disciplina, solamente que sus objetivos no son disciplinarios.

Yesurún Moreno: Muy interesante...

Marco Díaz: Te recomiendo encarecidamente un trabajo que además es muy bello, muy bonito y fácil de leer que es La corrosión del carácter (1998) de Richard Sennet, para comprender el funcionamiento de las sociedades postfordistas. Pero, volviendo a lo que te comentaba, en La ética del cuidado de sí como práctica de la libertad nos encontramos con que la distinción fundamental que en este punto preocupa a Foucault, no es aquella que tan bien trabaja en El sujeto y el poder, no es la distinción entre violencia y poder, en ambos casos considerados como formas de dominación, sino la distinción entre dominación y poder.

Y ahí se encuentra el meollo de la cuestión: cabe por primera vez en los textos de Foucault distinguir un poder que no es dominación (ni violenta, ni represiva, ni tecnológico-política, ni reguladora). Las prácticas de liberación pueden dar paso a prácticas de libertad en espacios políticos. La libertad ya no es concebida como mera resistencia al poder, sino como la práctica de una libertad política que se da formas validas y aceptables tanto de la existencia individual como de la sociedad política. Y esto significa que cabe en la historia, y, desde luego, al precio de la sangre de muchos hombres y mujeres, adquirir libertades y derechos. La historia ya no se concibe aquí como por ejemplo en Nietzsche, la genealogía, la historia (1971), como algo que procede de dominación en dominación, se trata ahora de un "análisis de la libertad", de una historia de la libertad. ¿Es inútil sublevarse? Puede ser leído bajo esta nueva luz: todas las libertades exigidas y conquistadas a lo largo de la historia tienen en la sublevación su punto de surgimiento y, por tanto, son posibles las sublevaciones que instalan libertad en la historia.

A partir de un determinado momento del itinerario foucaultiano parece difícil seguir manteniendo la idea de que la historia es, ante todo, la historia de una dominación, así como la idea de que la política es la continuación de la guerra por otros medios.

Este es un tema muy interesante, porque esto que señalas es justamente lo que te permite salir de la lectura de Carlos Fernández Liria, muy centrada 
en Vigilar y castigar, $^{8}$ de esa lectura según la cual, grosso modo, en Foucault finalmente estamos enteramente atrapados en la dominación, cambiarían los protagonistas de ésta, pero en ningún caso el escenario. El escenario es siempre el mismo.

$\mathrm{Y}$, sin embargo, como te digo, en estos últimos textos me parece que se abren otras posibilidades que están siendo trabajadas por muchos especialistas; y es a partir de aquí que puede producirse una cierta rehabilitación del derecho en Foucault, no solamente la apertura a la cuestión ética y a la efectividad de la crítica (una ética que ya no sería una ilusión y una crítica que ya no sería ideología), sino también, insisto, del derecho. Hay un investigador muy notable en Brasil, Márcio Alves, que ha escrito un libro titulado Michel Foucault et le Droit (2014) donde muestra un planteamiento de la cuestión del derecho, a partir de los pronunciamientos de actualidad de su última época, en la línea de lo que yo defiendo, aunque no se trata exactamente de lo mismo. La cuestión es que ahora empieza a hacerse una lectura de Foucault más cercana a la Ilustración, a la Ilustración críticamente asumida, vía Kant, a través de la lectura que emprende Foucault de los textos políticos de Kant. Fundamentalmente ¿Qué es la Ilustración? (1784) y la segunda parte de El conflicto de las facultades (1798) (extrañamente Foucault no considera para su proyecto de ontología de la actualidad la obra crítica kantiana, particularmente la Crítica de la razón pura (1787), como si en la obra crítica se jugara tan sólo una "analítica de la verdad", y en ningún caso una intervención de actualidad, en el estricto sentido que tiene en Foucault esta expresión). Por cierto, son los mismos textos que Hannah Arendt utiliza para organizar su lectura kantiana, su lectura de Kant fundamentada en el carácter político del juicio, o sea, en la idea de que la filosofía política de Kant se juega en la Crítica del Juicio (1790). De manera que, por tanto, la Crítica del Juicio no podría considerarse ni un libro de estética, ni un libro que, en su segunda parte, trata de cuestiones de biología, sino un texto en el que se está jugando lo político. Y a este respecto es muy interesante observar cómo Foucault también se está centrando en algunos de sus últimos trabajos sobre Kant en esos mismos textos de filosofía política que emplea Hannah Arendt, aunque extrañamente Foucault no los vincula con la Crítica del Juicio.

No sé si has oído hablar de Luis Alegre, fue secretario general de Podemos en la Comunidad de Madrid; tiene un libro maravilloso en el que habla mucho sobre la significación política del juicio en Kant, una significación que a mí me parece que también puede rastrearse en Foucault,

${ }^{8}$ Ver Fernández Liria, Carlos, Sin vigilancia y sin castigo. Una discusión con Michel Foucault, Madrid, Libertarias/Prodhufi, 1992. 
y desde luego en Hannah Arendt. Su título es El lugar de los poetas (2017). No tiene desperdicio para estos asuntos.

Yesurún Moreno: Cambiando de tercio... ¿En qué medida cree usted que la obra de Foucault tiene una vocación pedagógica? Me refiero a la frase de Foucault: "Todos mis libros son pequeñas cajas de herramientas". ¿Cómo interpreta estas palabras del francés?

Marco Díaz: Vamos a ver, la palabra "pedagogía" tiene mucho peligro, y los pedagogos tienen todavía más peligro... Entonces, si entendemos por pedagogía algo que tiene que ver con una "paideia" y por paideia algo muy cercano a lo que hacía Sócrates, a saber, una tarea basada en crear las condiciones críticas para la formación de una autonomía, que es la autonomía del otro, sí podría sostenerse que el pensamiento foucaultiano tiene una vocación pedagógica. Pero entonces el asunto no es aquí, en el marco de una relación con la verdad, conducir a los otros o manipularlos, sino participar en la creación de las condiciones para una resistencia a la dominación, que persiste en un cierto grado en nuestras sociedades, y para una práctica de la libertad en condiciones de igualdad. Y, para ello, es necesario un blindaje de la institución de enseñanza pública, y de poderosas estructuras jurídicopolíticas no secuestradas por los poderes salvajes del mercado y por las leyes de la oferta y la demanda. Y, en este sentido, es necesario incorporar a la lectura foucaultiana de la cuestión del poder (y pasando por esta cuestión) una apreciación de la noción del poder como institución pública, que sólo aparece al final de su itinerario de una manera muy vaga.

Yesurún Moreno: Una suerte de mayéutica...

Marco Díaz: ¡Eso es! Yo creo que esa vocación está presente en Foucault -que yo me resisto a llamar pedagogía- cuando habla de la filosofía como crítica. No como una crítica teórica del conocimiento que llevara a distinguir en este campo la verdad de la falsedad. ¡No! se trata de una crítica práctica en la que se halla en juego la constitución de un sujeto político. Es ahí donde se percibe clarísimamente la fuerza del pensamiento de Foucault. Te pones a leer a Foucault y desde luego aprendes muchas cosas, muchos conocimientos, es innegable que era un mar de erudición, pero ante todo te forma como sujeto político, como un sujeto capaz de actuar y de intervenir en el mundo, en tanto te relacionas críticamente con los saberes, con los poderes, con los otros y contigo mismo.

Por eso dice: de lo que se trata con la crítica como problematización es de participar en la formación de una voluntad política -lo dice él así literalmente- en una entrevista que se llama El cuidado de la verdad (1984).

Este es el punto. Foucault se resiste a ser leído como un autor productor y monopolizador del sentido de una obra, que un comentario habría de 
desvelar. Es en este sentido que Foucault no es un autor, sino un dispositivo textual de problematización. Sus libros, sus entrevistas, sus conferencias, sus pronunciamientos públicos, sus cursos están ahí como herramientas de formación de una voluntad política.

Yesurún Moreno: De hecho, Foucault prefería hablar no de lectores, sino de usuarios (que verdaderamente quisieran usar sus textos).

Marco Díaz: Hombre claro, los textos no están ahí para ser santificados, sino para ser usados e interpretados bajo las condiciones del lector que participa en la producción del sentido. Dicho esto, ello no significa que a partir de un texto dado se pueda decir cualquier cosa. El sentido se produce en el juego de la materialidad del texto con el presente de unos lectores que se exponen a los efectos de dicha materialidad (se trata de la lectura como una práctica de pensamiento, como un ejercicio de meditación). Y en ese juego tiene lugar una actualidad. Es interesante al respecto consultar la conferencia: Qu'est-ce que la Critique? Crítica y Aufklärung, en ella Foucault va a indicar que uno de los puntos de anclaje de lo que llama la actitud de no ser gobernado de tal modo (no en absoluto ni tanto) es la libre interpretación de la Biblia, tal como era sostenida en la Reforma protestante, frente a su lectura doctrinal. Tenemos aquí un punto de anclaje hermenéutico de la actitud crítica, que exige el espacio público del mundo de los lectores. Sin este espacio público no es que no se pueda llegar a leer libremente, es que no se puede llegar a pensar. La existencia misma del pensamiento, no su mera transmisión, depende de esta publicidad. Foucault era muy consciente de la necesidad de esta publicidad cuando señaló más o menos lo siguiente: no hay nada más peligroso que un sistema político que pretende prescribir la verdad. La función del dire vrai (un decir la verdad a la política, que es un decir efectivo) no ha de tomar la forma de la ley como también sería vano creer que ella reside de pleno derecho en los juegos espontáneos de la comunicación en la sociedad civil. La tarea del dire vrai es pues un trabajo de problematización infinito: respetarlo en su complejidad es una obligación de la que ningún poder puede hacer economía. Salvo imponiendo el silencio de esa servidumbre ${ }^{9} .$. que incuba la sublevación.

Yesurún Moreno: ¿Bajo qué presupuesto metodológico Foucault "mata" al hombre en Les mots et les choses de 1966? ¿Qué extrae de ello?

¿Cuál es el presupuesto o cuál es el axioma a partir del cual...? Evidentemente es un axioma crítico. Quiero decir, Foucault no está interesado en que se devaste a los seres humanos en el mundo o algo así, Foucault está interesado en neutralizar una cierta interpretación de la realidad dominante

\footnotetext{
${ }^{9}$ Consultar Dits et écrits 4, p. 678.
} 
en el siglo XX -y que surge en el siglo XIX- de carácter antropológico. Una interpretación, que Foucault considera estéril y paradójica teóricamente y devastadora en sentido práctico, en la cual el Hombre, ser finito, ocupa extrañamente el lugar de Dios, ser infinito: finitud fundamental, el hombre como un "soberano sumiso", que oscila en el plano teórico entre lo positivo y lo fundamental, lo empírico y lo trascendental, el cogito y lo impensado, el retorno y el retroceso del origen. En el plano práctico esta interpretación habría conducido a una de las grandes aporías de nuestra modernidad: ahí donde el hombre ha llegado a reconocerse, fundamento, centro y medida de todas las cosas, ahí, por lo mismo, ha devenido objeto de instrumentalización ilimitada. Pero esta interpretación ha entrado hoy en crisis abriendo una nueva posibilidad, desde luego, para proseguir el camino de la deshumanización total, al desconocer los fundamentos de esta crisis, que no tienen que ver tanto con el proyecto moderno e ilustrado, cuanto con su abandono y aniquilación. Pero también abre a una nueva consideración de la humanitas. Porque no está dicho que humanitas y humanidad tengan que relacionarse necesariamente con la tradición decimonónica del hombre como sujeto (mucho menos con Dios como fundamento). Tenemos una tradición de la humanitas que está por cierto también en La crítica del juicio (1790)-, que entronca con toda la tradición renacentista, humanista y que se remite en el tiempo hasta Cicerón, por ejemplo, donde el humanismo no es aquel que criticara Heidegger, Derrida, Foucault o Deleuze.

Entonces, lo que creo es que Las palabras y las cosas (1966) trata de desactivar ese humanismo decimonónico para promover otra interpretación de la realidad en la cual haya una oportunidad para los seres humanos, las cosas y la naturaleza. Es un tema un poco complicado...

Yo no creo que en Foucault haya una antropología, pero creo que el Foucault final replantea la cuestión del sujeto en términos de libertad. En esta cuestión del sujeto no se está jugando el ser del sujeto, su esencia o la posición del hombre en el mundo, sino que en general tenga lugar ser, en la riqueza de sus articulaciones y en la diversidad de sus legislaciones. Se trata de una problematización libre y de una interpretación que responde a una incitación de la realidad que abre el espacio de una relación con cosas (que no son meros bienes de consumo), y de relaciones con otros (que no son ni objetos de uso ni bienes de consumo), pero también de una relación de sí consigo como poder y deber ante "lo que es" (se trata de un soi que es cuerpo y que es vida, que es materialidad, pero que también es un poder de relacionarse consigo mismo, y en cierto modo de sobreponerse a su facticidad, actuando sobre ella y transformándola). Se trata del poder del pensamiento como actividad crítica, como trabajo crítico del pensamiento 
sobre sí mismo. Opera aquí una cierta forma de distanciamiento en relación a lo "dado", que se opone tajantemente al gesto de la meditación cartesiana devenida método. El reto es el siguiente: ¿cómo encarar eso que dice Foucault de la problematización como historia de las problematizaciones, a saber, que se trata aquí de una historia y de un análisis de la libertad "en el doble sentido del genitivo", sin caer en el gesto cartesiano y en su retoma hegeliana, teniendo en cuenta que el sujeto en Foucault ni se diluye en la historia ni termina por reconocerse en ella? Toma de distancia, retroceso, objetivación y libertad son características de la problematización en su sentido reflexivo, pero también lo son en Descartes. El reto como dice Potte-Bonneville es pensar una duda que no postule el derecho-privilegio de un ego cogito.

Es el problema de la crítica. Si nos tomamos en serio que hay crítica (Foucault dice: eso existe), si nos tomamos en serio que hay acontecimientos del pensamiento, tenemos que tomar en serio también la posibilidad de un cierto distanciamiento respecto a nosotros mismos y que, en consecuencia, no podamos considerarnos hijos -sin más- de nuestro tiempo y de nuestra política, pues podemos intervenir sobre nuestro tiempo y sobre nuestra política, transformándolos, y además transformándolos con criterios que no son de dominación, sino de libertad. A partir de esta cuestión habría que releer los textos del curso 1982 Hermenéutica del sujeto en los que Foucault distingue la reflexividad del método de aquella propia de la meditación. Así como el curso del 1984 donde Foucault trabaja las diferencias entre otro mundo/otra vida y mundo otro/vida otra.

Yesurún Moreno: Aún más, Foucault ahonda en esta cuestión cuando afirma: "el tema central de mi investigación no es el poder, sino el sujeto"...

Marco Díaz: ¡Eso es! La cuestión del sujeto, pero no como una cuestión antropológica. La cuestión del sujeto sin una teoría del sujeto previa, sin que en ella domine el postulado paradójico del hombre, ser finito como sujeto y objeto. Pero tampoco ninguna forma de metafísica del infinito.

Yesurún Moreno: ¿Qué supone en su opinión la obra Vigilar y castigar (1975) dentro de la trayectoria de Foucault? Miguel Morey sostiene que esta significa "el corte definitivo con la etapa arqueológica".

Marco Díaz: El corte definitivo con lo que se ha llamado la "etapa" arqueológica y acaso con "la ilusión del discurso autónomo". Lo que pasa es que algún especialista podría decir: pero esto se vendría gestando ya desde el año 1970 en su discurso inaugural con motivo de la toma de posesión de su cátedra en el Collège de France, y aún en la Arqueología del saber y más allá. Este es el peligro de las lecturas cronológicas del pensamiento de Foucault: que las "etapas" fácilmente llegan a concebirse como partes extra partes de un mero agregado que crecería por adición de partes externas, 
que luego terminan por sistematizarse de un modo genético, y esto no me parece de recibo, si atendemos con cuidado al movimiento del pensamiento foucaultiano y a su método, es decir, a su peculiar y original modo de estar en camino. Ciertamente se puede llegar a afirmar que en el Orden del discurso esto ya aparece, pero ¿cómo? ¿en germen? El poder ya estaría ahí, implícita y germinalmente, estaría incluso en Historia de la locura (1961) y, aún más, estaría también la ética. A mi juicio hay una sistematicidad del pensamiento foucaultiano, pero esa sistematicidad no es ni genéticodeductiva, ni dialéctica, se trata de una sistemática de la simultaneidad y, al tiempo y sin contradicción, de la transformación del pensamiento. Esto es quizá lo más difícil de pensar: este al tiempo y sin contradicción del sistema y la transformación, el movimiento de un pensamiento que se articula sobre tres ejes, irreductibles, pero indisociables: el pensamiento es saber, es poder, pero es también relación de sí consigo, pensamiento que se piensa a sí mismo, tarea crítica del pensamiento sobre sí mismo; es, al tiempo y sin contradicción, forma y actividad de problematización. "Problematización" -no "creación", no "representación", no "conocimiento" ni "acción", ni siquiera "deconstrucción"- es la extraña palabra elegida por Foucault para dar cuenta, de un modo original, de la sistematicidad propia de la actividad del pensamiento. Pero sí, dicho esto, estaría de acuerdo con Morey: hay discontinuidad, hay por tanto initium en el pensamiento, hay efectivo movimiento. Vigilar y castigar (1975) es uno de esos libros de Foucault en que se pone de manifiesto esta irrupción del pensamiento, un texto donde se exhibe la apertura a una nueva dimensión no planificada de antemano: Ya no se trata del saber como episteme, sino del "dispositivo" saber-poder. Y en ese sentido sí es verdad que ahí encontramos una intervención de Foucault muy clara sobre la política (en la política, mejor dicho) y en relación con una concepción general del poder que a él no le satisfacía, desdoblada en la concepción liberal (contractualista) -tomando el contractualismo de una manera muy, muy simplificada- y en la concepción marxista (considerada de un modo no menos simplista, bajo la metáfora de la infraestructura y la superestructura muy ajena al Marx maduro). Y es ahí donde el pensamiento foucaultiano interviene: el poder es dominación, el poder no tiene que ver con "libertad", con algo así como un pacto entre libertades que da lugar al poder político, el resultado de un contrato entre sujetos libres que ceden libremente parte de su libertad -ajena a toda condición material- en pro de la seguridad. El poder no sería esto, no sería un derecho que se enajena libremente, como uno se enajena de una propiedad, el poder es, más bien, el hecho de la dominación, pero esta dominación no se puede entender de manera reduccionista, en ese modo, por ejemplo, en que el poder solo 
reproduce relaciones de producción determinadas y opera en un nivel ideológico-superestructural. Foucault dice no, no, no, el poder es productivo, opera en la instancia de la producción, no superestructuralmente, y eso quiere decir que el poder produce relaciones económicas, produce fuerza de trabajo, produce relaciones de producción y en esa medida es necesario otro análisis de la dominación capitalista, básicamente. Lo que pasa es que el pensamiento en Foucault es un movimiento que, sin superar o dejar de lado otras dimensiones, se abre a nuevas que no estaban dadas de antemano y que desplazan y resignifican las anteriores. Hay que atender al pasaje, y al modo en que se produce el pasaje del dispositivo a la "problematización", esa noción de la que Foucault dice que es su noción "esencial" y la que otorga la "forma común" a sus investigaciones.

Yesurún Moreno: ¿Cuáles son los elementos principales a parte del dispositivo poder-saber en la obra Vigilar y castigar, que en buena medida plantean una lectura renovadora de la idea de poder? ¿Cuáles fueron sus aportaciones más notables?

Marco Díaz: En primer lugar, una concepción no sustancialista del poder, el poder no como una propiedad, sino como una relación, eso es fundamental, absolutamente fundamental. La idea de que el poder no es originariamente represivo ni violento, que la especificidad del poder no es ni la violencia ni la represión, sino la producción y más en particular -como te digo- la producción de la fuerza productiva misma. Estas son las ideas más originales, ahí me parece que Foucault comprende que un análisis serio de la especificidad del poder ha de atender a su carácter productivo y no represivo y meramente violento. Pero esto entraña un grave problema, una aporía con la que Foucault se enfrenta desde el momento en que afirma que hay resistencias. Esta aporía marca el límite de la dimensión del poder y la apertura de la nueva dimensión de la relación de sí consigo, la apertura hacia un algo que no es poder, que no estaba contenido en el poder y que lo desplaza de manera profunda, es decir, la nueva dimensión entraña una modificación esencial, una reproblematización de la cuestión del poder.

Yesurún Moreno: Llegados a este punto, no sé si conoce la obra Cárcel y fábrica (1977) -sobre los orígenes del sistema penitenciario- de los italianos Dario Melossi y Massimo Pavarini; su planteamiento difiere del de Foucault ya que ellos sugieren que el origen de la cárcel surge con el sistema capitalista y que su función era producir estrictamente fuerza de trabajo.

No debemos olvidar que, pese a que Foucault ha sido muy crítico con una cierta ortodoxia marxista que detestaba, él es un voraz crítico del capitalismo y del sistema capitalista. Y eso se ve perfectamente en $L a$ 
voluntad de saber que es un texto que está en la misma óptica del poder que Vigilar y castigar. Cuando habla del biopoder, del poder sobre la vida, poder en parte disciplinario en parte biopolítico, habla del modo de ejercicio propio del poder en una sociedad capitalista como la nuestra. Así que, por tanto, no tiene sentido en otro contexto. Esto es fundamental. Foucault haciendo una crítica del biopoder, está haciendo una crítica -como no puede ser de otra manera- al sistema capitalista y, por ende, difícilmente podemos considerar un Foucault fascinado (y no más bien horrorizado) por los nuevos modos de producción de subjetividad del capitalismo postindustrial.

Yesurún Moreno: ¿Se refiere al gobierno de sí como empresario de sí mismo?

Marco Díaz: ¡Eso es una locura! Vamos a ver, Foucault es crítico con todo eso. No tiene ningún sentido. Foucault no está fascinado con todo eso, jal contrario! Es sumamente crítico, y si en El nacimiento de la biopolítica (curso 1978-1979), que es donde habla del neoliberalismo, Foucault no está siendo explícitamente crítico es porque está haciendo historia, entonces digamos que tiene que ser metodológicamente neutro. Pero uno sólo tiene que ver los textos que rodean a la impartición del curso Nacimiento de la biopolítica para atender al tono crítico con el que Foucault se está enfrentando a las sociedades securitarias, a nuestras sociedades, en las que los seres humanos, desencantados, han llegado a creer que no hay nada que hacer, que no hay alternativa posible, al seguirle el juego a la paradoja de la voluntad del homo oeconomicus. Pero Foucault no acepta el planteamiento del problema de la voluntad en estos términos, como tampoco acepta el planteamiento del problema de la voluntad en un modo cartesiano. Hay un después del "momento cartesiano" que no es Descartes, y que está siendo sepultado por la identificación, a izquierda y derecha, del ethos de modernidad con el proyecto cartesiano. Es aquí donde hay que ubicar la modernidad de Foucault y sus últimas lecturas de Kant.

Yesurún Moreno: En relación a esto último, si tuviera que definir o pudiera trazar una línea de relación entre los conceptos de libertad, poder y resistencia o si se prefiere, poder, cuerpo y revolución ¿Cómo lo haría? ¿Cómo encajan tales elementos?

Marco Díaz: Vamos a ver, desde luego, la resistencia... la cuestión de la resistencia, pero tal como aparece en el planteamiento más matizado del último Foucault -en La ética del cuidado de sí como práctica de la libertad (1984) dice expresamente: ahora tengo una visión mucho más clara de todo esto y mucho más matizada de lo que es el poder. Y ahí dice que la resistencia, como práctica de liberación, solo tiene sentido en un contexto 
determinado, a saber, en un contexto de dominación, como puede darse en muchos países del eje sur de nuestro planeta.

Lo interesante es que nos encontramos, leyendo simultáneamente $E l$ sujeto y el poder y La ética del cuidado de sí como práctica de la libertad, con que Foucault dice lo siguiente: esa resistencia -que además tiene por fundamento una cierta libertad en el juego del poder como dominación productiva a través de una conducta- y esa práctica de liberación, en el marco de una situación de enfrentamiento, en la que hay violencia y no puede no haberla, ya no da paso necesariamente a un escenario en el que la paz civil consolida y prolonga, mediante medios técnicos y silenciosos, los efectos de la guerra, los efectos de la dominación decidida en la batalla. Es decir, las prácticas de liberación y la resistencia abren o pueden abrir un escenario político de relaciones de poder con mínimos de dominación, un espacio en el que caben prácticas de libertad que hay que controlar o limitar crítica y jurídicamente (y, por tanto, institucional y públicamente), a fin de garantizar la simetría en las relaciones de poder presentes en toda sociedad y en toda la sociedad. Y esto me parece importantísimo para entender que no todo está perdido, para entender que la historia no procede de dominación en dominación y que la violencia no es siempre el germen de una nueva violencia, sino que en la revolución -también habría que matizar mucho el término revolución- se está jugando también la posibilidad de que se instalen nuevas libertades y nuevos derechos. Por descontado, estos pueden retroceder en el orden fáctico. Este es el problema del texto sobre Polonia: La experiencia moral y social de los polacos no puede borrarse. Es decir, fácticamente, la conquista de esos derechos puede retroceder, puedes conquistar derechos y luego estos pueden ser suspendidos o abolidos, pero lo que no puede ser borrado en la historia es la experiencia de lo intolerable de esa abolición. Para esto ya no hay paso atrás, se ha instalado una línea de progreso - por la que se puede medir un regreso- en relación con aquellas situaciones que ahora se perciben como absolutamente intolerables, y que sólo hemos llegado a tolerar, no porque de suyo sean tolerables, sino simplemente por hábito (Foucault hablará del peligro que amenaza en todo lo que es habitual). Desde el momento en que los seres humanos se ponen a hablar sobre sus vidas, desde el momento en que se rompe, aunque sólo sea por un instante, el aislamiento y el silencio al que condena la dominación, desde el momento en que se genera una esfera pública, aunque sea muy frágil y precaria, una nueva sensibilidad comienza a instalarse y organizar nuestras vidas, que nos hace decir: esto es intolerable. Por ejemplo, en la película Las sufragistas se narra cómo las mujeres en Inglaterra obtienen el derecho al voto. Ellas conquistaron algo en la historia, consiguieron 
generar un debate público que dio lugar a una nueva sensibilidad social. A partir de ese momento podrá haber en el mundo retrocesos en relación con el sufragio universal, pero esto necesariamente solo podrá percibirse como una injusticia, incluso entre esos que se encargan de cometerla, utilizando el secreto y las estrategias del silencio.

Yesurún Moreno: En el trabajo que le comentaba hice también otra analogía empleando una frase de un personaje de Juego de Tronos, un eunuco consejero del rey llamado Varys: "El poder es una sombra (...) y a veces, un hombre muy pequeño puede proyectar una sombra muy grande”... ¿Por qué esta analogía? En primer lugar, porque no se centra en el carácter lesivo y prohibitivo del poder, sino en la sombra misma. Foucault a mi juicio pretende escudriñar en la sombra del poder y no en aquello visible que nos deslumbra. Por otro lado, ese "un hombre muy pequeño puede proyectar una sombra muy grande" hace hincapié en la pequeñez y la incorporeidad. Me explico, esa pequeñez nos hace partícipes a todos del poder, nos invita a disputar el poder en un plano no ciertamente de igualdad, pero si de una relativa horizontalidad que es lo verdaderamente interesante del planteamiento de Foucault y lo que abre ese anhelo de revolución en base a una injusticia previa que es percibida como tal...

Marco Díaz: Las hay y son injusticias corporales, quiero decir, el cuerpo ya no puede más cuando, por ejemplo, se ve sometido a jornadas laborales interminables. Entonces, ¿qué es lo que hace la razón cuando se da cuenta de que tiene un cuerpo, cuando experimenta en su cuerpo lo intolerable? Inventa el derecho, como dice Nuria Sánchez Madrid, los derechos sociales, los derechos laborales, ¿Qué está pasando, pues, en nuestra sociedad? Que nos encontramos con un retroceso en relación a todo eso, que implica la aniquilación de un cuerpo. Un cuerpo que se queja porque tiene límites y que no es infinitamente moldeable. Un cuerpo con el que no se puede hacer cualquier cosa.

Ahí está, pues, el foco de la resistencia: en la peculiaridad de los seres humanos de ser un cuerpo, en esa vulnerabilidad de los seres humanos que impone límites infranqueables al poder -otra expresión que utiliza Foucault-.

Yesurún Moreno: Quizá su planteamiento sea más ambiguo y no solo se centre en esa vulnerabilidad irreductible de los cuerpos, sino en su fortaleza intrínseca. A saber, en Microfísica del poder dirá: "pero desde el momento en que el poder ha producido este efecto, en la línea misma de sus conquistas, emerge la reivindicación del cuerpo contra el poder, la salud contra la economía, el placer contra las normas morales de la sexualidad, el matrimonio, el pudor, y de golpe aquello que hacía al poder fuerte se 
convierte en aquello por lo que es atacado". Resulta interesantísimo ya que esto luego se traduce en los Nuevos Movimientos Sociales.

Marco Díaz: Es un texto muy bonito. Claro, te refieres a los Nuevos Movimientos Sociales y a las nuevas reivindicaciones sociales que se centran en el cuerpo, pero ahí es donde yo complementaría todo esto con la idea de que hay que hacer una cierta ontología de los cuerpos. A estos discursos y este activismo políticos les falta un discurso más sólido sobre el cuerpo. Porque, claro, justamente cuando se habla de la flexibilidad de los cuerpos y la indeterminación de los cuerpos, quizá se le está haciendo el juego al neoliberalismo que justamente lo que quiere es cuerpos flexibles y cuanto más flexibles mejor.

Tenemos que tratar de articular políticas con una noción de cuerpo como cuerpo verdaderamente resistente. Como decía Chesterton al respecto: "con el pelo rojo de una niña [es decir, con el cuerpo] prenderé fuego a toda la civilización moderna". En este sentido, me parece fundamental una reflexión más sistematizada sobre el cuerpo y sobre las coberturas sociales, institucionales que necesita el cuerpo y que se están perdiendo.

Yesurún Moreno: Marco, ha sido un placer contar con su ayuda, siento haberle robado tanto tiempo...

Marco Díaz: Yo espero que te haya servido de algo, tiendo a hablar mucho, pero la verdad es que todas las preguntas que me has hecho me parecen muy pertinentes y además tocando temas apasionantes, no solamente sobre Foucault, sino en general de nuestra actualidad. Así que un placer, ha sido un verdadero placer, espero haberte ayudado.

Yesurún Moreno: Lo cierto es que me ha ayudado muchísimo, de veras.

Marco Díaz: No dudes en ponerte en contacto conmigo para cualquier otra cosa.

Yesurún Moreno: ¡Estamos en contacto! Un saludo y muchísimas gracias de nuevo. 
